\title{
Intestinal stoma in patients with colorectal cancer from the perspective of 20-year period of clinical observation
}

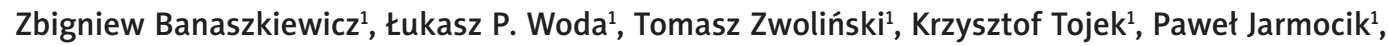 \\ Arkadiusz Jawień \\ ${ }^{1}$ Division of General, Gastroenterological, Colorectal and Oncological Surgery, Department of Vascular Surgery and Angiology, \\ Collegium Medicum in Bydgoszcz, Nicolaus Copernicus University in Torun, Poland \\ ${ }^{2}$ Department of Vascular Surgery and Angiology, Collegium Medicum in Bydgoszcz, Nicolaus Copernicus University in Torun, \\ Poland
}

Prz Gastroenterol 2015; 10 (1): 23-27

DOI: $10.5114 /$ pg.2015.49107

Key words: colostomy, colorectal cancer.

Address for correspondence: Tomasz Zwoliński MD, Division of General, Gastroenterological, Colorectal and Oncological Surgery, Department of Vascular Surgery and Angiology, Collegium Medicum in Bydgoszcz, Nicolaus Copernicus University in Torun, 75 Ujejskiego St, 85-168 Bydgoszcz, Poland, phone: +48 796860 656, e-mail: tomaszos87@wp.pl

\begin{abstract}
Introduction: Intestinal stoma is a procedure most often performed in patients with colorectal cancer.

Aim: To identify the percentage of patients with colorectal cancer in which the intestinal stoma was performed.

Material and methods: We retrospectively analysed 443 patients treated during a 20-year period (1994-2013) due to colorectal cancer, in which the intestinal stoma was made during the first surgical intervention.

Results: In the second analysed decade, a significant decrease in the percentage of created stomas, definitive stomas in particular, was observed. Stomas were made significantly more often in patients with a tumour located in the rectum, the left half of the colon, and in patients undergoing urgent surgeries. An increased incidence of intestinal stomas was associated with a higher severity of illness and higher proportion of unresectable and non-radical procedures. The definitive stomas were significantly more often made in men and in patients with tumours located in the rectum, whereas temporary stomas were created significantly more often in patients undergoing urgent operations.

Conclusions: In the last decade (2004-2013) the number of intestinal stomas in patients operated due to colorectal cancer was significantly reduced.

\section{Introduction}

The execution of colostomy in the treatment of colorectal cancer (CRC) has been known since the late eighteenth century [1]. Despite significant progress in the detection of CRC (screening, better availability of endoscopy) and the treatment of this disease (neoadjuvant therapy, staplers) there is still a significant proportion of patients in whom creating an intestinal stoma is required. An intestinal stoma is performed during the treatment of colon cancer, the treatment of other advanced neoplasms infiltrating the intestine, and while treating inflammatory bowel disease. It may be a definitive stoma (e.g. in case of malignant ovarian tumour), a temporary stoma performed when

safe primary anastomosis is impossible to perform (e.g. Hartmann's surgery), or as temporary protection of an intestinal anastomosis (e.g. a loop ileostomy after restorative proctocolectomy). Most often an intestinal stoma is performed in patients with cancer of the middle and lower part of the rectum and patients with complicated forms of colorectal cancer [2-4]. In spite of the increasingly wide information about the disease and significantly better access to modern diagnostics, still about $15-30 \%$ of patients with CRC are operated with symptoms of "acute abdomen" [5]. The safest and most recommended method of operation is Hartmann's procedure because of its radical nature and the relatively small number of postoperative complications $[6,7]$.
\end{abstract}


Definitive intestinal stoma is performed only in patients who cannot obtain a lower safety margin of resection of the rectum (rectal amputation) and in patients with unresectable changes. In some patients after resectional operation, a temporary stoma is formed with the assumption of creating the anastomosis thereafter, or as a protective stoma after performing the anastomosis at the time of its healing [8]. In practice, a substantial proportion of these patients did not have reconstructive procedures performed. This is due to the progression of the underlying disease or the patient's reluctance to undergo re-surgery. This reluctance results from a large number of complications after restorative surgeries and good care of the stoma and refunded, good quality ostomy appliance [9-12]. There is also a group of patients scheduled for restorative surgery in which, as a result of difficult local conditions, the attempt to perform scheduled operation fails [13]. In 2012, in the United States 143,460 patients were diagnosed with CRC and 51,690 deaths were declared because of this. One in 8 patients in the course of treatment had an intestinal stoma performed [14]. There is no accurate data on the proportion of stomas created in patients with CRC in the Polish population.

\section{Aim}

The aim of this study was to identify the percentage of patients with colorectal cancer in which the intestinal stoma was performed.

\section{Material and methods}

We analysed the records of all consecutive patients treated for CRC in the period from February 1994 to February 2013 in one centre, in which an intestinal stoma was made during the first surgical intervention. Histopathological examination was performed in the Department of Pathology, University Hospital No. 2 in Bydgoszcz. Due to the severity of such an operation, the group was divided into patients with low (first and second clinical-pathological degree) and high (third and fourth degree) stage of CRC.

\section{Statistical analysis}

Statistical analysis was performed using Statistica 10 software. For unrelated variables the Pearson's $\chi^{2}$ test was used. A confidence level of $p<0.05$ was considered statistically significant.

\section{Results}

During 20 years of follow-up (1.02.1994-1.02.2013) 1710 patients, diagnosed with CRC for the first time, were treated surgically. A complete medical record was obtained in 1378 (80.58\%) patients. In this group, during the first surgery, every third patient $(443 / 32,15 \%)$ had an intestinal stoma created - including definitive stoma, which was made in 259 (18.80\%) patients.

In the whole group of patients with CRC there were 821 (59.58\%) elderly patients with a slightly higher proportion of men than women (697 vs. 681 patients). There were no significant differences in the amount of created stomas according to sex and age of the patients. At the time of qualification for surgical treatment, there were 808 (58.64\%) patients with significant comorbidities. Cardiovascular disease (151/34\%) and diabetes mellitus type II (78/17.61\%) were observed the most often. In patients in whom an intestinal stoma was made, comorbidities occurred in a similar proportion as in patients without a stoma (57.34\% vs. 59.25\%, $p>0.05)$ (Table I). In 539 (39.11\%) patients the tumour was located in the rectum, and in these patients the frequency of formation of stoma was significantly increased compared to patients with tumours of the colon $(56.22 \%$ vs. $16.69 \%$, $p<0.05)$. In patients operated due to rectal cancer, amputation was performed in 138 of them (25.6\%). In the first decade it was made in 77 of 268 patients (28.3\%), and in the second decade in 61 of 271 patients (22.51\%). Meanwhile, for patients with tumours of the colon, stoma was made three times more often with left-sided location of the tumour $(72.51 \%$ vs. $27.49 \%, p<0.05)$. Two hundred and thirty (16.69\%) patients underwent surgery with indications of urgency, and in this group of patients intestinal stoma was created significantly more often compared to patients undergoing planned operation (63.91\% vs. $25.78 \%, p<0.05)$ (Table I).

In the analysed group of patients $(n=1378)$ a resection treatment was performed in 1199 (83.36\%) patients. Unresectable and non-radical treatments were significantly more often associated with the necessity of forming a stoma $(67.70 \%$ vs. $32.40 \%, p<0.05$, and $52.03 \%$ vs. $47.97 \%, p<0.05$, respectively). High stage CRC was diagnosed in 655/47 (53\%) patients. In this group of patients, an intestinal stoma was significantly more frequently made $(60.46 \%$ vs. $39.54 \%, p<0.05)$ - Table II.

In the second decade of observation (2004-2013) of patients with CRC, a significant reduction of the percentage of performed intestinal stoma was observed (35.45\% vs. $29.62 \%, p=0.02)$. Among patients with newly made stoma, there were 259 (58.47\%) patients with a definitive stoma. In the second decade of observation, the proportion of patients with a definitive stoma was significantly lower (43.24\% vs. $56.76 \%$, $p<0.05)$, although the percentage of patients with a high clinical stage of CRC was similar (54.81\% vs. 45.19\%, $p>0.05$ ) - Table III.

We compared two groups of patients: patients with newly made definitive stoma and those in whom a tem- 
Table I. Characteristics of the study group

\begin{tabular}{|c|c|c|c|c|}
\hline Parameter & & $\begin{array}{c}\text { Stoma }+ \\
n(\%)\end{array}$ & $\begin{array}{c}\text { Stoma - } \\
n(\%)\end{array}$ & Value of $p$ \\
\hline Comorbidities $(n=808)$ & & $254(57.34)$ & $554(59.25)$ & 0.500216 \\
\hline \multirow[t]{4}{*}{ Comorbidities } & Cardiovascular $(n=497)$ & $151(34.09)$ & $346(37.01)$ & 0.291834 \\
\hline & Pulmonary $(n=43)$ & $13(2.93)$ & $30(3.21)$ & 0.784672 \\
\hline & Diabetes type II $(n=221)$ & 78 (17.61) & $143(15.29)$ & 0.274455 \\
\hline & Renal insufficiency $(n=49)$ & $13(2.93)$ & $36(3.85)$ & 0.391272 \\
\hline \multirow[t]{2}{*}{ Sex } & Female $(n=681)$ & $203(29.81)$ & $478(70.19)$ & 0.066127 \\
\hline & Male $(n=697)$ & $240(34.43)$ & $457(65.57)$ & \\
\hline \multirow[t]{2}{*}{ Age } & $<65$ years $(n=557)$ & $175(31.42)$ & $382(68.58)$ & 0.632842 \\
\hline & $\geq 65$ years $(n=821)$ & $268(32.64)$ & $553(67.36)$ & \\
\hline \multirow[t]{4}{*}{ Tumour localisation } & Rectum $(n=539)$ & $303(56.22)$ & $236(43.78)$ & $<0.000001$ \\
\hline & Colon $(n=839)$ & $140(16.69)$ & $699(83.31)$ & \\
\hline & Right $(n=428)$ & $27(6.31)$ & 401 (93.69) & $<0.000001$ \\
\hline & Left $(n=411)$ & $113(27.49)$ & $298(72.51)$ & \\
\hline \multirow[t]{2}{*}{ Surgery } & Planned $(n=1148)$ & $296(25.78)$ & $852(74.22)$ & $<0.000001$ \\
\hline & Urgent $(n=230)$ & $147(63.91)$ & 83 (36.09) & \\
\hline
\end{tabular}

Table II. Influence of extent of surgery and severity of the disease on the frequency of performing an intestinal stomas

\begin{tabular}{llll} 
Parameter & \multicolumn{1}{c}{$\begin{array}{c}\text { Stoma }+ \\
n(\%)\end{array}$} & $\begin{array}{c}\text { Stoma }- \\
n(\%)\end{array}$ \\
\hline $\begin{array}{l}\text { Surgeries } \\
(n=1378)\end{array}$ & Resective $(n=1199)$ & $322(26.86)$ & $877(73.14)$ \\
\cline { 2 - 4 } & Non-resective $(n=179)$ & $121(67.60)$ & $58(32.40)$ \\
\cline { 2 - 4 } & Radical $(n=1082)$ & $289(26.71)$ & $793(73.29)$ \\
\cline { 2 - 4 } & Non-radical $(n=296)$ & $154(52.03)$ & $539(47.97)$ \\
\hline Stage & Low $(n=723)$ & $184(2545)$ & 39.00001 \\
\cline { 2 - 4 } & High $(n=655)$ & $259(39.54)$ & $396(60.46)$
\end{tabular}

porary stoma was created. There were no significant differences in patient age, comorbidities, and present stage of CRC. In contrast, the definitive stoma was made significantly more frequently in males (154/64, $17 \%$ vs. $86 / 35,83 \%, p<0.05)$ and in patients with tumour localised in the rectum $(223 / 73 \%$ vs. $36 / 25.71 \%$, $p<0.05)$. A temporary stoma was created significantly more often in patients undergoing urgent surgery $114 / 77.55 \%$ vs. 33/22.45\%; $p<0.05$ (Table IV).

\section{Discussion}

In Poland, the total number of performed intestinal stomas remains constant, despite progress in diagnosis (much better accessibility to endoscopic examinations, screening for early detection of (RC) and more modern treatment of diseases of the colon (staplers, saving treatments). According to estimates in our country, annually 5-6 thousand new stomas are made, and there
Table III. Clinical stage of colorectal cancer and type of intestinal stoma performed in the study group

\begin{tabular}{llccc} 
Parameter & \multicolumn{1}{c}{$\begin{array}{c}\text { 1994-2003 } \\
n(\%)\end{array}$} & $\begin{array}{c}\text { 2004-2013 } \\
n(\%)\end{array}$ & $\begin{array}{c}\text { Value } \\
\text { of } p\end{array}$ \\
\hline $\begin{array}{lllll}\text { Clinical } \\
\text { stage CRC }\end{array}$ & Low & $302(41.77)$ & $421(58.23)$ & 0.200765 \\
& $(n=723)$ & & \\
\cline { 2 - 4 } & $\begin{array}{l}\text { High } \\
(n=655)\end{array}$ & $296(45.19)$ & $359(54.81)$ & \\
\hline $\begin{array}{l}\text { Intestinal } \\
\text { stoma } \\
(n=443)\end{array}$ & $\begin{array}{l}\text { Temporary } \\
(n=184)\end{array}$ & $65(35.33)$ & $119(64.67)$ & 0.000009 \\
\cline { 2 - 4 } & $\begin{array}{l}\text { Definitive } \\
(n=259)\end{array}$ & $147(56.76)$ & $112(43.24)$ & \\
& & & &
\end{tabular}

are about 35,000 people currently living with a stoma [15-17]. In the Kuyavian-Pomeranian Province the number of people living with a stoma over the past 5 years (2009-2013) has maintained at a similar level (2077 to 2270). Most stomas are performed in patients with CRC, 
Table IV. Results of the study

\begin{tabular}{|c|c|c|c|c|}
\hline \multicolumn{2}{|l|}{ Parameter } & $\begin{array}{c}\text { Temporary stoma } \\
n(\%)\end{array}$ & $\begin{array}{c}\text { Definitive stoma } \\
n(\%)\end{array}$ & Value of $p$ \\
\hline \multicolumn{2}{|c|}{ Comorbidities $(n=254)$} & $103(40.55)$ & $151(59.45)$ & 0.626168 \\
\hline \multirow[t]{4}{*}{ Comorbidities } & Cardiovascular $(n=151)$ & $63(41.72)$ & $88(58.28)$ & 0.954231 \\
\hline & Pulmonary $(n=13)$ & $5(38.46)$ & $8(61.54)$ & 0.819452 \\
\hline & Diabetes $(n=78)$ & $28(35.90)$ & $50(64.10)$ & 0.265661 \\
\hline & Renal insufficiency $(n=13)$ & $8(61.54)$ & $5(38.46)$ & 0.137396 \\
\hline \multirow[t]{2}{*}{ Sex } & Female $(n=203)$ & $98(48.28)$ & $105(51.72)$ & 0.008099 \\
\hline & Male $(n=240)$ & $86(35.83)$ & $154(64.17)$ & \\
\hline \multirow[t]{2}{*}{ Age } & $<65$ years $(n=175)$ & $70(40)$ & $105(60)$ & 0.596258 \\
\hline & $\geq 65$ years $(n=268)$ & $114(42.54)$ & $154(57.46)$ & \\
\hline \multirow{4}{*}{$\begin{array}{l}\text { Tumour } \\
\text { localisation }\end{array}$} & Rectum $(n=303)$ & $80(26.40)$ & $223(73.60)$ & $<0.000001$ \\
\hline & Colon $(n=140)$ & $104(74.29)$ & $36(25.71)$ & \\
\hline & Right $(n=27)$ & $18.6(6.67)$ & $9(33.33)$ & 0.313335 \\
\hline & Left $(n=113)$ & $86(76.11)$ & 27 (23.89) & \\
\hline \multirow[t]{2}{*}{ Stage } & $\operatorname{Low}(n=184)$ & $83(45.11)$ & $101(54.89)$ & 0.198253 \\
\hline & High $(n=259)$ & $101(39.00)$ & $158(61.00)$ & \\
\hline \multirow[t]{2}{*}{ Surgeries } & Elective $(n=296)$ & $70(23.65)$ & $226(76.35)$ & $<0.000001$ \\
\hline & Urgent $(n=147)$ & 114 (77.55) & $33(22.45)$ & \\
\hline
\end{tabular}

although there is also an upward trend in patients after surgeries due to inflammatory bowel disease. In our patients with CRC, stoma was made significantly more often in patients undergoing urgent operation, with tumour localised in the rectum, and in patients with left-sided location of the colon cancer $(p<0.05)$.

In the whole group of patients in whom a stoma was made, there were significantly fewer resectional and radical surgeries performed ( $p<0.05)$. In $13 \%$ of patients $(179 / 1378)$ the intestinal stoma was performed as the only procedure due to the high clinical stage of CRC. The literature emphasises that the number of stomas created in patients with CRC is increasing [18]. In our centre, in the observed group of patients with CRC, in the second decade of observation (2004-2013), significantly fewer intestinal stomas were made $(p=0.02)$ including definitive stomas $(p<0.05)$. In the first decade of observation (1994-2003) among patients with newly formed stoma, temporary stoma was made in $30 \%$ of patients, while in the second decade it was made in more than half of patients (51.52\%). Such a high percentage of temporary stomas in our centre is due to the high percentage of operated patients with complicated CRC (17\%) and preventive stomas created in operated patients with a cancer of the central and lower part of the rectum. Operations performed with urgent indications are often performed in difficult conditions, in patients with limited chance for accurate diagnostics, and therefore the ending of the surgery by intestinal stoma is the safest procedure. A preventive stoma is performed usually in the treatment of the lower and middle part of the rectum, often in patients after neoadjuvant radiotherapy. These stomas, according to the opinion by Nurkin et al., prevent septic complications; however, the group of patients with rectal cancer in which they are performed is too numerous [16]. In the analysis by Snijders et al. it was performed in $70 \%$ of patients, and according to the authors this procedure does not affect the incidence of anastomotic leakage [15].

In the study by Richardson et al., after the analysis of definitive stomas created in 10 hospitals in Canada, it was found that the selection of definitive stoma was influenced by three factors: male sex, tumor location in the rectum, and tumor stage [8]. In our study, a definitive stoma was also performed significantly more often in men and in patients with rectal cancer. It was made slightly more frequently in patients with a high stage of cancer (61.00\% vs. 54.89\%); however, a statistical significance was not shown. According to Tokode, a definitive stoma should always be considered in older patients, with significant comorbidities and advanced cancer [18].

It seems that in Poland there is a chance for a further decrease in the proportion of patients treated for $\mathrm{CRC}$, in which there is a need for an intestinal stoma. The way to achieve this goal is to improve early detection of CRC (screening), which should contribute to a re- 
duction in the proportion of patients undergoing urgent operations and patients with unresectable changes and reduce the proportion of amputation of the rectum. In the centres participating in the pilot program testing the quality of treatment of rectal cancer in Poland, the percentage of abdominoperineal amputation of the rectum was relatively low (20.7\%) despite the large number of patients operated on at an advanced stage of the disease (55.4\%) [19].

\section{Conclusions}

In the last decade (2004-2013) the number of intestinal stomas, in particular definitive stomas, in patients operated due to CRC was significantly reduced. In patients with CRC an intestinal stoma was made significantly more often in patients with a tumour located in the rectum and in the left half of the colon as well as in patients undergoing urgent interventions. An increased incidence of intestinal stomas in patients with CRC was associated with a higher grade of CRC and a higher percentage of unresectable and non-radical procedures. Definitive intestinal stoma in patients with CRC was made significantly more often in men and in patients with tumours located in the rectum; meanwhile, temporary stoma was made significantly more frequently in patients undergoing urgent surgeries.

\section{Conflict of interest}

The authors declare no conflict of interest.

\section{References}

1. Skeps R, McMullen CK, Wendel CS, et al. Changes in body mass index and stoma related problems in the elderly. J Geriatr Oncol 2013; 4: 84-9.

2. Wong SK, Jalaludin BB, Morgan MJ, et al. Tumor pathology and long-term survival in emergency colorectal cancer. Dis Colon Rectum 2008; 51: 223-30.

3. Corman JM, Odenheimer DB. Securing the loop - historic review of the methods used for creating a loop colostomy. Dis Colon Rectum 1991; 34: 1014-21.

4. Lim SW, Kim HJ, Kim CH, et al. Risk factors for permanent stoma after low anterior resection for rectal cancer. Langenbecks Arch Surg 2013; 398: 259-64.

5. Seah DW, Ibrahim S, Tay KH. Hartmann procedure: is it still relevant today? ANZ J Surg 2005; 75: 436-40.

6. Maggiori L, Bretagnol F, Lefèvre JH, et al. Conservative management is associated with a decreased risk of definitive stoma after anastomotic leakage complicating sphincter-saving resection for rectal cancer. Colorectal Dis 2011; 13: 632-7.

7. Szczepkowski M. Good stoma (Polish). Postępy Nauk Medycznych 2006; 5: 240-50.

8. Richardson DP, Porter GA, Johnson PM. Population-based use of sphincter-preserving surgery in patients with rectal cancer: is there room for improvement? Dis Colon Rectum 2013; 56: 704-10.
9. Szczepkowski M, Borycka K, Bielecki K, Niemirowicz-Szczytt M. Wyniki ogólnopolskiego prospektywnego badania epidemiologicznego pacjentów ze stomią [Polish]. Proktologia 2009; 10: 94-107.

10. Golicki D, Styczeń P, Szczepkowski M. Quality of live in stoma patients in Poland: multicentre crossectional study using WHOQOL-BREF questionnaire. Przegl Epidemiol 2013; 67: 491-6.

11. Floodeen $\mathrm{H}$, Lindgren $\mathrm{R}$, Matthiessen $\mathrm{P}$. When are defunctioning stomas in rectal cancer surgery really reversed? Results from a population-based single center experience. Scand J Surg 2013; 102: 246-50.

12. Hüser N, Michalski CW, Erkan M, et al. Systematic review and meta-analysis of the role of defunctioning stoma in low rectal cancer surgery. Dig Surg 2008; 25: 473-80.

13. Tan WS, Tang CL, Shi L, Eu KW. Meta-analysis of defunctioning stomas in low anterior resection for rectal cancer. Br J Surg 2009; 96: 462-72.

14. Golicki D, Styczeń P, Szczepkowski M. Quality of life in stoma patients in Poland: multicentre cross-sectional study using WHOQOL-BREF questionnaire. Przegl Epidemiol 2013; 67: 491-6.

15. Snijders HS, van den Broek CB, Wouters MW, et al. An increasing use of defunctioning stomas after low anterior resection for rectal cancer. Is this the way to go? Eur J Surg Oncol 2013; 39: 715-20.

16. Nurkin S, Kakarla VR, Ruiz DE, et al. The role of faecal diversion in low rectal cancer: a review of 1791 patients having rectal resection with anastomosis for cancer, with and without a proximal stoma. Colorectal Dis 2013; 15: 309-16.

17. Tan WS, Lim JF, Tang CL, Eu KW. Reversal of Hartmann's procedure: experience in an Asian population. Singapore Med J 2012; 53: 46-51.

18. Tokode OM, Akingboye A, Coker O. Factors affecting reversal following Hartmann's procedure: experience from two district general hospitals in the UK. Surg Today 2011; 41: 79-83.

19. Ulrich $A B$, Seiler $C$, Rahbari N, et al. Diverting stoma after low anterior resection: more arguments in favor. Dis Colon Rectum 2009; 52: 412-8.

Received: 17.05 .2014

Accepted: 5.09.2014 